\title{
DETERMINANTES DE LA INVERSIÓN EXTRANJERA DIRECTA CHINA EN LATINOAMÉRICA
}

\author{
DETERMINANTS OF CHINA FOREIGN DIRECT INVESTMENT IN LATIN AMERICA
}

\section{RESUMEN}

Objetivo: Analizar el flujo de inversión extranjera directa de la República Popular China desde el 2008 al 2017 en 7 países latinoamericanos: Argentina, Brasil, Chile, Colombia, México, Perú y Uruguay. Método: La investigación es de tipo cuantitativo, no experimental, longitudinal de panel, de alcance descriptivo y explicativo. Se analizaron las siguientes variables: Producto Interno Bruto, balanza comercial, instituciones, inflación, distancia de Beijing a la capital del país latinoamericano y los recursos naturales, desde el 2008 al 2017. Resultados: Los resultados de la investigación muestran que la única variable que por el momento atrae la inversión china a Latinoamérica es el tamaño de la economía. Conclusiones: Por consiguiente, se concluye que aquellos países que cuenten con un PIB más elevado, serán mayormente atractivos para la deslocalización de la inversión China.

Palabras clave: China; determinantes; flujo; inversión; Latinoamérica.
Luis Alfredo Ávila-López Universidad Autónoma de Baja California Tijuana, México ORCID: https://orcid.org/0000-0002-5391-2551

Correo electrónico: avila.luis@uabc.edu.mx

Jorge Alfonso Galván-León Universidad Autónoma de Baja California Tijuana, México ORCID: https://orcid.org/0000-0003-4264-3058

Correo electrónico: jgalvan@uabc.edu.mx

Carolina Zayas-MárQuez Universidad Autónoma de Baja California Tijuana, México ORCID: https://orcid.org/0000-0001-9572-3444 Correo electrónico: carolina.zayas@uabc.edu.mx

[Recibido: 11/08/2020 Aceptado: 03/12/2020 Publicado: 28/12/2020]

\begin{abstract}
Objective: Analyze the flow of foreign direct investment of the People's Republic of China from 2008 to 2017 in 7 Latin American countries: Argentina, Brazil, Chile, Colombia, Mexico, Peru and Uruguay. Method: The research is quantitative, non-experimental, longitudinal panel, descriptive and explanatory scope. Seven variables were analyzed: gross domestic product, trade balance, inflation, distance from Beijing to the capital of the Latin American country and natural resources, from 2008 to 2017. Results: Research results show that the only variable that currently attracts Chinese investment to Latin America is the size of the economy. Conclusions: The variable that seems to determine the investment in this region it lead based on the size of the economy, which was represented in this analysis with the GDP.
\end{abstract}

Keywords: China; determinants; flow; investment; Latin America.

(c) Los autores. Este artículo es publicado por la Revista Quipukamayoc, Universidad Nacional Mayor de San Marcos. Este es un artículo de acceso abierto, distribuido bajo los términos de la Licencia Creative Commons Atribución-NoComercial-Compartirlgual 4.0 Internacional.(http://creativecommons.org/licenses/by-nc-sa/4.0/), que permite el uso no comercial, distribución y reproducción en cualquier medio, siempre que la obra original sea debidamente citadas. 


\section{INTRODUCCIÓN}

Históricamente, la Inversión Extranjera Directa (IED) se ha definido como un catalizador del desarrollo económico de países emergentes. Los dos ejes rectores son sin duda la generación de empleo y el capital que recibe el país, pero el aspecto más importante es la derrama tecnológica que incide en el capital humano de los países a donde llega la inversión.

Existen numerosos estudios sobre los impactos de la IED en el desarrollo de una economía (Mendoza, 2011, Rendón y Ramírez, 2017, Téllez-León y Venegas-Martínez, 2018, Giraldo y Obando, 2012) y algunos de los argumentos son la relación entre la IED y el tamaño del mercado en países en desarrollo.

Durante varias décadas la inversión extranjera directa provenía tradicionalmente de Europa, Estados Unidos y Japón; con el paso del tiempo, se fueron incorporando economías desarrolladas, como las de Canadá y Australia. Pero recientemente se incorporó China al escenario de las inversiones.

Silva y Teixeira (2018) hacen énfasis en el ascenso económico de China y cómo la derrama económica es uno de los factores que pone a prueba el orden financiero internacional sobre todo en Latinoamérica. China ya es la nación comercial influyente y la segunda economía más poderosa del mundo. Barboza (2010) Si continúan las tendencias actuales, para el 2025, será la economía más grande. La inversión extranjera directa externa ha ido incrementando con el avance de los flujos comerciales, alcanzando su pico en el año 2000.

En los reportes de la Comisión Económica para América Latina y el Caribe (CEPAL, 2016), se analiza cómo algunos gobernantes ven a la IED como una forma de impulsar la formación de capitales. Especialmente, en América Latina y en el Caribe, este tipo de inversiones ha desencadenado un patrón productivo y ha significado el pase de entrada al contexto global y negociaciones con países poderosos, gracias a la explotación de los recursos naturales; además, de otro aspecto de suma importancia: la actividad de manufactura.

El presente trabajo de investigación se conduce a través de la siguiente interrogante: ¿Qué factores económicos determinan la llegada de la inversión china en Argentina, Brasil, Chile, Colombia, México, Perú y Uruguay? El objetivo primordial es establecer las variables que permiten una mayor inversión extranjera directa de China hacia los países latinoamericanos. Las hipótesis propuestas para este trabajo son dos: Hipótesis 1: la inversión extranjera directa china es atraída por países con instituciones pobres. Hipótesis 2: la inversión extranjera directa china es atraída por países con abundantes recursos naturales.

El trabajo se aborda desde la perspectiva metodológica cuantitativa y es de corte no experimental. Se analizan siete variables que permiten establecer la relación existente entre la inversión de China hacia países latinoamericanos. La estructura del artículo presenta una parte introductoria donde se establece el planteamiento del problema, seguido se ofrece una revisión teórica que contextualiza la problemática. Enseguida se muestra el método y los materiales, que a su vez dan paso a los resultados y la discusión.

La influencia que genera la IED se refleja en las exportaciones de productos o partes de productos con alto valor agregado y con un avance científico y tecnológico cada vez mayor, esto gracias a la derrama de innovación y desarrollo. Es decir, para que esto suceda se requiere contar con recurso humano calificado, capacidades productivas y tecnológicas; además, de los marcos normativos, sistemas impositivos y contextos confiables con un buen ambiente social en donde efectivamente las empresas internacionales, trasnacionales y globales observen posibilidades de desarrollo y, posiblemente, capacidad para generar nuevos procesos.

Por otro lado, China se encuentra entre los países promotores de la IED y extiende sus capitales a diversas partes del mundo. Sus inversiones han aumentado considerablemente en los últimos años, por lo que se la considera como fuente de IED en un gran número de economías receptoras.

De acuerdo con Dollar (2017), China ha reconocido que la infraestructura es clave para el crecimiento de los países y que la financiación privada y los bancos de desarrollo existentes no son suficientes. Latinoamérica, una región rica en recursos naturales, ha sido clave para el crecimiento de China. En el 2018, los ingresos en América Latina rebasaron los 14 billones de dólares, donde Brasil fue el mayor receptor con 61 billones de dólares.

Para contextualizar, las inversiones salientes de China de los últimos treinta años advierten un incremento sustancial a partir de la crisis del 2008; ya que lograron su mayor repunte en el 2016 con un monto de 196 149,4 millones de dólares. Para el año 2019, se observó un detrimento en las inversiones que realizó China en el exterior, pues el registro fue de 117120 millones de dólares. Evidentemente, para el año 2020, y los subsecuentes, se presenta una tendencia a la baja; esto se prevé, al menos, hasta el 2022, año al que se proyectan alcanzar los efectos negativos de la crisis ocasionada por el covid-19.

Por otra parte, en cuanto a la inversión extranjera entrante a China, se percibe un incremento gradual y sostenido. Al 
igual que las inversiones salientes, pareciera que la crisis del 2008 catapultó las inversiones, dado que se presentan avances, aunque no sustanciales, previos a la crisis. Aun así, China pasó de recibir 4 366,3 millones de dólares en 1991, a recibir 141225 millones de dólares en 2019.

Queda pendiente observar el comportamiento de las inversiones en los años 2020, 2021 y 2022 con los efectos catastróficos de la actual crisis provocada por la pandemia. Este fenómeno será interesante de abordar con el objetivo de analizar la posición de China respecto a las inversiones que hará en otros países, particularmente en Latinoamérica, dadas las actuales condiciones económicas y políticas de China, país que reclama un espacio para liderar en el contexto global.

Se prevé que los flujos mundiales de la IED disminuyan. Una de las hipótesis en torno a este tema es que debido a las reglas de confinamiento que experimentaron algunos países, la producción y las cadenas de suministros se detuvieron y la producción mundial se ralentizó. Esto como consecuencia del cierre de establecimientos de todo tipo, medida tomada en aras de minimizar la propagación pandémica del virus SARS-CoV-2 y, con ello, retomar el curso normal de la economía mundial lo más pronto posible.

Sin duda la crisis provocada por el covid-19 ha reflejado efectos inmediatos en la IED; sin embargo, se espera que esta condición prevalezca durante varios años. El período de recuperación iniciará cuando las condiciones de oferta y demanda de los países y de las grandes empresas se normalicen, incluyendo los efectos provocados por las actuales condiciones de geopolítica globales. Se especula que gran parte del proceso de recuperación recaerá en las buenas relaciones que se cultiven entre empresarios y mandatarios, quienes - desafortunadamente - en la actualidad, desencadenan conatos de guerra fría señalados, en gran parte, a través de medios y redes sociales.

Ante este fenómeno es posible observar la interrelación existente entre los países al experimentar el efecto dominó sobre los flujos de la IED. Según el Informe sobre las inversiones en el mundo 2020, de la United Nations Conference on Trade and Development (2020), las perspectivas después del 2021 son inciertas. Se espera una trayectoria en forma de U, respecto a la recuperación de la IED, hacia su línea de tendencia anterior a la crisis antes del 2022; esto es posible, pero solo en el escenario más optimista. Mientras tanto, la incertidumbre económica y geopolítica parece dominar el panorama de inversiones a medio plazo. Por otra parte, en el escenario pesimista, un mayor estancamiento en el 2022 dejará el valor de la IED global muy por debajo del nivel del año 2019.
El debate que envuelve a la IED recae en que es uno de los principales elementos que deben tener los países interesados en recibir capitales en un sistema político y legal estable; además, de la concentración-proximidad considerablemente cercana a mercados extranjeros con potencial para invertir (Giraldo y Obando, 2012; Bittencourt y Domingo, 2002).

Tradicionalmente, la IED es considerada como una de las mayores contribuciones al crecimiento económico ya que estimula la formación de nuevos capitales. De acuerdo con los supuestos de Lautier y Moreau (2012) es posible definir la creación de capitales como la diferencia existente entre la IED y el valor de las fusiones y adquisiciones realizadas con otros países. Es decir, cuando una empresa extranjera adquiere una empresa nacional, esto representa una forma de IED; sin embargo, no se está creando un nuevo capital en el país que recibe la fusión.

Por otra parte, para que la IED represente un impacto positivo en el país receptor, existen dos principales alternativas. En primer lugar, que las empresas extranjeras contribuyan de manera directa e indirecta en la transferencia de tecnología, desarrollo de habilidades y capacitación de la mano de obra. En segundo término, que las empresas extranjeras actúen como un vínculo para establecer redes entre empresas domésticas y empresas globales para establecer redes de colaboración y de esta manera enriquecer y fortalecer las cadenas de valor, exponenciando la capacidad de las empresas domésticas a escalas internacionales y globales (Groot, 2018).

Otro hecho irrefutable sobre la inversión extranjera directa es que, además de los contextos legal y políticamente saludables, esta busca lugares con los recursos requeridos, bien sean recursos naturales, recursos humanos o recursos espacio- territoriales. Esto significa que el movimiento de la IED estará en función de la formación de capacidades científico-tecnológicas que, a su vez, al desarrollarse, atraerán cada vez mayor inversión del exterior con el objetivo de aprovechar y estimular estas capacidades. Por consiguiente, se evidencia la necesidad de establecer políticas públicas que potencien las capacidades locales del recurso humano y del entorno industrial.

La historia de cómo China dio el cambio de ser receptor a emisor de inversión extranjera directa comienza con lo que se conoce actualmente como China (oficialmente República Popular China), una región grande que estuvo compuesta por varias subregiones (Ávila-López, 2018) y comienzo del partido comunista liderado por Mao Zedong, quien realizó reformas encaminadas a estabilizar al país. Sin embargo, el cambio más trascendental se da después de la muerte de Mao, en 1976, cuando Deng Xiaopin llegó al poder y, eventualmente, logró convertirse en un 
líder supremo de China. En diciembre de 1978, en el Tercer Pleno del Comité Central, Deng consolidó su poder y dio inicio las reformas. La dinámica del crecimiento de la productividad y las cuñas intersectoriales desde 1978 al 2011 son muy diferentes a las de 1952 a 1978. (Cheremukhin et al., 2015). Una de esas políticas fue la llamada política de puertas abiertas, de finales de los años setenta, la cual provocó a una modesta IED externa. La liberalización asociada con la gira de Deng Xiaoping por el sur de China en 1992, y la estrategia Go Global iniciada en 1999 condujeron en aumentos de la IED externa (Kolstad y Wiig, 2012).

Los logros actuales de China encierran una historia larga y complicada, que como comenta Ávila-López (2018), se deben a las políticas de reforma y apertura al exterior aplicadas durante los últimos 35 años. Ante la coyuntura actual, China está actuando con firmeza para profundizar las reformas en todos los sectores, con miras a inyectar una nueva vitalidad al desarrollo del país.

La inversión extranjera directa china hacia el mundo, por años, se centró en regiones desarrolladas, como Europa, Estados Unidos, Australia y en zonas en desarrollo del sureste asiático. No obstante, recientemente se ha dirigido a América Latina, esto es lo que lleva a formular la siguiente pregunta de investigación ¿Qué factores económicos determinan la llegada de la inversión china a Argentina, Brasil, Chile, Colombia, México, Perú y Uruguay? Estudios previos, como el de Kolstad y Wiig (2012), demuestran que variables como la distancia, los recursos naturales o el Producto Interno Bruto (PIB) pueden incentivar las inversiones chinas.

Los países con la mayor proporción de IED china en América Latina son Brasil y Argentina; sin embargo, en 2018 vieron disminuir su recepción IED; mientras que Chile y Perú se convirtieron en los países más importantes en este sentido, recibiendo el $63,03 \%$ y el $16,31 \%$ de IED china en América Latina en este mismo año (Dussel, 2019).

La región de Latinoamérica ha transitado por etapas de aprendizaje económico- Corral y Anzola (1998) señalan que, en el caso de Colombia, desde la segunda mitad de la década del sesenta hasta inicios de los noventa, su política de inversión extranjera se caracterizó por las extensas restricciones de los flujos de capital, ya fuera por razones de índole macroeconómica o bien por proteger la industria nacional.

Cuenca (2003) menciona que en México la publicación, en 1973, de la Ley para promover la inversión mexicana y regular la inversión extranjera tenía como objeto: "Promover la inversión mexicana y regular la inversión extranjera para estimular un desarrollo justo y equilibrado y consolidar la independencia económica del país" (p. 246). Se establece las características de los inversionistas y se determina los sectores económicos en los cuales cada uno de ellos puede participar; esta ley fue modificada con el reglamento expedido en mayo de 1989.

Ávila-López et al. (2018) presentan una comparación de la balanza comercial de México con otras regiones del mundo y analizan cómo América Latina presenta mayor déficit comercial que Asia, de la cual China es responsable con un $53,3 \%$. Si se extrapola esta realidad a países de Latinoamérica se obtiene un resultado similar. Incrementar la inversión extranjera es una forma de ser parte de ese crecimiento económico que China presenta.

De acuerdo con Peters (2018), la inversión de China en Latinoamérica se sigue diversificando: recientemente, los países con la mayor participación de esta-Brasil y Argentina- vieron descender su recepción, mientras que Perú $y$, particularmente, Chile se convirtieron por mucho en los países más importantes al respecto, pues en el 2018 recibieron el 63,03\% y 16,31\%, respectivamente. Más allá del desplome de esta captación de recursos en Brasil y Argentina, también es notable su disminución en México en 2018 y con respecto al año anterior.

\section{MATERIALES Y MÉTODOS}

Para comprobar empíricamente la relación entre la inversión extranjera directa proveniente de China y las variables propuestas, se utilizó una metodología de tipo cuantitativo, no experimental, longitudinal de panel, de alcance descriptivo y explicativo. Utilizando el programa R. Se analizaron las siguientes variables: producto interno bruto, balanza comercial, inflación, distancia de Beijing a la capital del país latinoamericano y recursos naturales, desde el 2008 al 2017. Los datos provienen de fuentes públicas como la biblioteca electrónica del Fondo Monetario Internacional y el Informe sobre el desarrollo mundial, como de la base de datos del Banco Mundial, y para el análisis de la distancia entre la capital del país receptor y Beijing, estos proceden del Centre d'Études Prospectives et d'Informations Internationales. La muestra de países a analizar es: Argentina, Brasil, Chile, Colombia, México, Perú y Uruguay. Debido a que son los países latinoamericanos que mostraron información constante en los años del estudio. Por otro lado, las variables son representadas en la ecuación como sigue:

IED China $=\alpha+\beta_{1}$ Instituciones $+\beta_{2}$ Recursos Naturales + $\beta_{3}$ Instituciones $_{\mathrm{i}}{ }^{\star}$ Recursos Naturales $\left._{\mathrm{i}}\right)+\gamma$ Controles $+\varepsilon_{\mathrm{i}}$

Donde:

$\alpha$ : Nivel de significancia

$\beta_{1}$ : Instituciones 


\section{$\beta_{2}$ : Recursos Naturales}

$\beta_{3}$ : Instituciones ${ }_{i}{ }^{*}$ Recursos Naturales $_{i}$

$\gamma$ : Controles

$\varepsilon_{\mathrm{i}}$ : error

\section{RESULTADOS}

Se proponen las siguientes hipótesis: Hipótesis 1: la inversión extranjera directa china es atraída por países con instituciones pobres. Si la inversión china se dirige a países ricos en recursos naturales, esto probablemente refleja objetivos políticos y la Hipótesis 2: la inversión extranjera directa china es atraída por países con abundantes recursos naturales.

En la Tabla 1, se muestran los resultados obtenidos como producto de la matriz de correlación de las variables
Producto Interno Bruto (PIB), comercio, inflación, distancia, instituciones y recursos naturales. Al analizar las diferentes variables que pueden generar una mayor inversión de China hacia los países latinoamericanos en la tabla 2, de acuerdo con los resultados, paradójicamente, la relación entre estas variables tiene bajos niveles de significancia.

En concordancia con otras regiones del mundo, los resultados de la tabla 2 muestran que la única variable que se asocia significativamente con la IED china externa es el PIB del país receptor. En otras palabras, la IED china externa es atraída por países con grandes mercados. Ninguna de las otras variables explicativas es significativa. En particular, esta estimación encuentra sin efecto los recursos naturales del país anfitrión o el nivel institucional en la entrada de IED china.

Tabla 1

Matriz de correlación de variables analizadas

\begin{tabular}{|c|c|c|c|c|c|c|}
\hline & PIB & Comercio & Inflación & Distancia & Instituciones & Recursos N \\
\hline PIB & 1,0000 & & & & & \\
\hline Comercio & $-0,6470$ & 1,0000 & & & & \\
\hline Inflación & $-0,3050$ & $-0,5676$ & 1,00 & & & \\
\hline Distancia & $-0,1141$ & $-0,0144$ & 0,79 & 1,0000 & & \\
\hline Instituciones & 0,09 & 0,9 & 0,68 & 0,502 & 1,0000 & \\
\hline Recursos N & 0,18 & $-0,18$ & 0,45 & 0,651 & $-0,58$ & 1,0000 \\
\hline
\end{tabular}

Fuente: Elaboración propia

Tabla 2

Resultados de regresión de MCO, variable dependiente IED china externa 2008-2017

\begin{tabular}{lc}
\hline & Regresión \\
\hline PIB & $2,24 \mathrm{e}-11$ \\
\cline { 2 - 2 } & $4,10 \mathrm{E}-11$ \\
\cline { 2 - 2 } & 0,072 \\
\hline Inflación & $-0,079$ \\
\hline Distancia & 0,201 \\
\hline & $-0,179$ \\
\hline Instituciones & $-0,097$ \\
\hline & $-0,001$ \\
\hline Recursos N. & $-1,348$ \\
\hline
\end{tabular}

Fuente: Elaboración propia 
Los resultados de la muestra completa sugieren, por lo tanto, dos conjuntos principales de determinantes de la inversión extranjera directa externa de China: el tamaño del mercado y los recursos naturales junto con las instituciones pobres.

La única variable significativa es el PIB, esto que sugiere que la IED china en los países ricos está impulsada por el tamaño del mercado. Por esta razón, China desconoce en gran parte la región de América Latina, por lo tanto, es relativamente nueva en esta región.

\section{DISCUSIÓN}

Con el desarrollo del presente artículo, queda claro que, a pesar de existir determinantes para la presencia de inversión extranjera de China en otras regiones como el mundo desarrollado, África o Asia, en Latinoamérica con la muestra de países y considerando las variables analizadas, China aún no tiene camino claro sobre dónde invertir. Los resultados son escasos debido a que solo la variable que parece determinar la inversión en esta región se conduce con base en el tamaño de la economía, y que fue representada en este análisis a través del PIB. Esta situación ya había sido analizada por Connelly y Cornejo (1992) quienes señalaban cómo la relación de China con América Latina, así como su interés, ha recibido muchos esfuerzos por parte de académicos y políticos de todas partes del mundo; sin embargo, no ha podido lograr el nivel que ha alcanzado con países europeos o bien con Estados Unidos. Uno de los propósitos de este análisis fue demostrar que, si los países latinoamericanos desean atraer la IED desde China, no se deben confiar solo en mantener niveles de comercio saludables, inflación controlada, instituciones fuertes o abundancia de recursos naturales; sino en tener presencia en el radar de China, dándose a conocer por medio de ferias, intercambios educativos, tecnológicos, pero sin dejar de lado la parte comercial y económica que actualmente se está trabajando. Las dos hipótesis fueron rechazadas ya que no se encontraron indicios de que la inversión China sea atraída por países con instituciones pobres, ni tampoco por países con abundantes recursos naturales. En conclusión, China actualmente figura como una economía grande y que crece año con año de manera exponencial, este hecho ha generado un espacio en las esferas globales de los negocios, las transacciones internacionales y las inversiones, tanto en ejercicios de entrada como de salida con el resto del mundo. La clave para formar parte de la cartera de países receptores de inversiones chinas es mantener altos niveles del PIB de manera constante, además de contar con un amplio mercado que sea atractivo para recibir no solo inversiones, sino también productos y servicios de alta calidad e intensivos en alta tecnología.

\section{REFERENCIAS}

Aguirre, R., Muñoz, L., y Roldán, R. (2020). Determinantes de la inversión extranjera directa en América Latina: una visión desde la economía administrativa. Revista Economía y Política, 36-49.

Ávila-López, L. (2018). La experiencia en la creación de un Sistema Nacional de Innovación en China y México, programa de becas para investigadores sobre china del centro de estudios China-México 2018. Consultado el 3 de mayo de 2020 de https://dusselpeters.com/ CECHIMEX/20190807_La_experiencia_en_la_creacion_de_un_SNI_en_China_y_Mexico.pdf

Ávila-López, L., Zayas-Márquez, C. y Beltrán-Noriega, S. (2018). La balanza de pagos en México de 1993 a 2016: Un análisis por regiones. Investigación en Ciencias Administrativas, 8(15), 50-65

Banco Mundial (2020). Informe sobre el Desarrollo Mundial 2020: El comercio al servicio del desarrollo en la era de las cadenas de valor mundiales (Washington: Banco Mundial, 2020).

Barboza, D. (2010). China passes Japan as second-largest economy. The New York Times, 15. En: https://huongduongtxd.com/china.pdf

Bittencourt, G., y Domingo, R. (2002). Los determinantes de la IED y el impacto del Mercosur. Documento de Trabajo/FCS-DE; 4/02.

Centre d'Études Prospectives et d'Informations Internationales. (2017). http://www.cepii.fr/

Cheremukhin, A., Golosov, M., Guriev, S., y Tsyvinski, A. (2015). The Economy of People's Republic of China from 1953, CEPR Discussion Paper No. 10764.

Corral, L., y Anzola, M. (1998). Inversión extranjera directa en Colombia, 1990-1998. Revista de Planeación y Desarrollo, 29(1), 149-176.

Comisión Económica para América Latina y el Caribe [CEPAL]. (2016). Inversión Extranjera Directa en América Latina y el Caribe 2016. En: https://repositorio.cepal. org/bitstream/handle/11362/40213/7/S1600664_es.pdf

Connelly, M., y Cornejo Bustamante, R. (1992). China-América Latina: génesis y desarrollo de sus relaciones.

Cuenca, S. (2003). Competitividad e inversión extranjera directa en México. Análisis Económico, 18(37), 241-256. 
Dollar, D. (2017). The future direction of Chinese investment. East Asia Forum Quarterly 47 (1), 21

Dussel, E. (2019). China's foreign direct investment in Latin America and the Caribbean: conditions and challenges. Universidad Autónoma de México

Fornés, G. y Mendez, A. (2018). The China-Latin America axis: Emerging markets and their role in an increasingly globalised world. Springer.

Garriga, A. (2017). Inversión extranjera directa en México: comparación entre la inversión procedente de los Estados Unidos y del resto del mundo. Foro internacional, 57(2), 317-355.

Giraldo, D. y Obando, H. (2012). Determinantes y efectos de la inversión extranjera directa: revisión de literatura. Ensayos de economía, 22(41), 109-128.

Groot, O (2018). Inversión extranjera directa y su papel en el desarrollo económico. En Dussel Peters, E. Cadenas Globales de Valor. Metodología, Teoría y Debates. 10(32) 111-134.
Kolstad, I. y Wiig, A. (2012). What determines Chinese outward FDI? Journal of World Business, 47(1), 26-34.

Mogrovejo, J. (2005). Factores determinantes de la inversión extranjera directa en algunos países de Latinoamérica. Revista latinoamericana de desarrollo económico, (5), 51-82.

Peters, E. (2020). Monitor de la OFDI china en América Latina y el Caribe 2020.

Silva, G., Gomes, M. y Teixeira, E. (2018). Efecto derrame del crecimiento de China en América del Sur: un análisis basado en el comercio internacional. Revista CEPAL.(1), 47-62

United Nations Conference on Trade and Development (2020). World Investment Report 2020. International production Beyond the Pandemic. https://unctad.org/ system/files/official-document/wir2020_en.pdf 